\title{
Proposal of a novel classification of leukocorias
}

This article was published in the following Dove Press journal:

Clinical Ophthalmology

28 June 2012

Number of times this article has been viewed

\author{
Marcia Beatriz Tartarella' \\ Glória Fátima Britez- \\ Colombi' \\ João Borges Fortes Filho \\ 'Department of Ophthalmology, \\ Congenital Cataract Section, \\ Federal University of São Paulo, \\ São Paulo SP, Brazil; ${ }^{2}$ Department \\ of Ophthalmology, Hospital de \\ Clínicas de Porto Alegre, Federal \\ University of Rio Grande do Sul, \\ Porto Alegre RS, Brazil
}

Background: To report a case series of nine patients presenting with leukocoria without lens opacification or retrolental abnormalities and to propose a novel classification for leukocoria.

Methods: An institutional and retrospective study including a case series of patients assisted in the Congenital Cataract Section of Federal University of São Paulo, Brazil, during the period between 2005 and 2010 with prelenticular leukocoria and clear lens.

Results: Nine patients younger than 4 years old presented with the diagnosis of unilateral prelenticular opacities without cataract formation. Echography in all patients revealed no posterior segment or lens abnormalities in the affected eye. Among the patients, three had idiopathic prelenticular membrane, two presented with juvenile xanthogranuloma with secondary pupillary membrane, one had persistent fetal pupillary membrane, one had prelenticular membrane due to congenital toxoplasmosis, one presented with pupillary membrane due to hyphema caused by iris hemangioma, and one had anterior segment persistent fetal vasculature.

Conclusions: This case series of patients presented unilateral prelenticular leukocoria without lens opacification or posterior segment abnormalities. Several etiologies were associated with this condition. The correct diagnosis is important in order to avoid clear lens extraction. A new classification of leukocoria is proposed herein including: prelenticular leukocoria, lenticular leukocoria, retrolenticular leukocoria, and mixed presentation leukocoria.

Keywords: leukocoria, prelenticular, pupillary membrane, children, retinoblastoma, congenital cataract

\section{Introduction}

The presence of leukocoria, a white pupil or altered red-reflex test in children, is relevant ophthalmological evidence deserving prompt diagnosis and treatment when necessary. The correct diagnosis of leukocoria needs to be carefully clarified once a retinoblastoma is diagnosed in conjunction with a white pupil or altered red reflex, and is considered a life-threatening disease..$^{1-3}$

Some authors classify leukocoria in two major groups: lenticular leukocoria (lens opacities), or retrolenticular leukocoria (retinoblastoma and pseudoretinoblastomas). ${ }^{4}$

This study aims to present the clinical features of patients with prelenticular leukocoria without lens opacification and to propose a new classification of leukocoria including those with prelenticular opacities, and leukocoria with mixed presentation.

\section{Methods}

A case series of patients presenting with leukocoria was retrospectively reviewed. The patients were referred between 2005 and 2010 to the Congenital Cataract Section of 
the Department of Ophthalmology, Federal University of São Paulo, Brazil, to undergo cataract surgery. Ophthalmological evaluation included slit-lamp examination, binocular indirect ophthalmoscopy, visual acuity measurements, and ocular ultrasonography. Surgery was performed when necessary and these procedures will be described in the reported cases. Partial time occlusion therapy was indicated in all cases.

\section{Case I}

A 3-month-old male presented with abnormal red reflex and unilateral leukocoria in his right eye. Visual acuity was logarithm of the minimum angle of resolution (LogMAR) 1.30 (Snellen 20/395) in the affected eye and LogMAR 0.67 (Snellen 20/95) in the normal eye. Slit-lamp examination disclosed the presence of iris remnants at pupillary area without lens opacification. Posterior segment ultrasound was normal in the affected eye. Clinical diagnosis was prelenticular leukocoria caused by a persistent fetal pupillary membrane.

\section{Case 2}

A 3-month-old girl, born from cesarean section, presented with unilateral leukocoria in her left eye. Her mother developed active systemic toxoplasmosis during pregnancy. Visual acuity was LogMAR 0.120 (Snellen 20/250) in the affected eye. Slit-lamp examination showed a fibrin membrane over the pupillary edge, posterior synechias, and a clear lens. Intraocular pressure was normal in both eyes. Indirect ophthalmoscopy disclosed an isolated focal retinal scar at the inferior-temporal quadrant without inflammatory activity. Clinical presumed diagnosis was prelenticular leukocoria caused by uveitis due to congenital toxoplasmosis.

\section{Case 3}

A 3-year-old boy presented with leukocoria in his left eye. He was submitted to a trabeculectomy surgery in this same eye due to glaucoma related to juvenile xanthogranuloma when 2 years old. Best-corrected visual acuity was LogMAR 0.86 (Snellen 20/145) in the affected eye. External examination disclosed yellowish dermatological lesions on his face, thorax, and both lower limbs. Slit-lamp examination showed buphthalmos, superior filtering bleb, yellowish iris nodules, white membrane partially affecting the pupillary area, and clear lens. Intraocular pressure was $5 \mathrm{mmHg}$ in both eyes without medication for glaucoma. Indirect ophthalmoscopy and posterior segment ultrasound were normal in the affected eye. Clinical diagnosis was prelenticular membrane secondary to the resolution of an anterior chamber hemorrhage (hyphema) caused by juvenile xanthogranuloma (Figure 1).

\section{Case 4}

A 6-month-old girl presented with unilateral leukocoria in left eye. The patient's parents noted an altered red reflex of 2 weeks duration. The estimated visual acuity at presentation was equivalent to the light perception in the affected eye. Slitlamp examination disclosed yellowish iris nodules and a thick prelenticular membrane at the pupillary area preventing the lens observation. Surgery was performed in order to excise the membrane. Peeling off the pupillary membrane by clear cornea approach of the anterior chamber revealed a clear lens. A spontaneous anterior chamber hemorrhage occurred 20 days after the initial procedure. The hyphema improved with clinical treatment but relapsed after 3 months. Clinical diagnosis was prelenticular fibrinoid membrane secondary to hyphema due to juvenile xanthogranuloma in her left eye.

\section{Case 5}

A 14-month-old boy presented with unilateral leukocoria in his left eye. At initial examination, his visual acuity was LogMAR 1.45 (Snellen 20/415). Slit-lamp examination showed a dense membrane affecting the pupillary area, resembling an anterior capsular cataract. There was no red reflex. Ultrasound demonstrated a normal vitreous cavity in the affected eye. A limbic incision was performed and the anterior chamber was filled with viscoelastic substance. Peeling of the pupillary membrane was performed. This procedure revealed a clear lens behind the membrane.

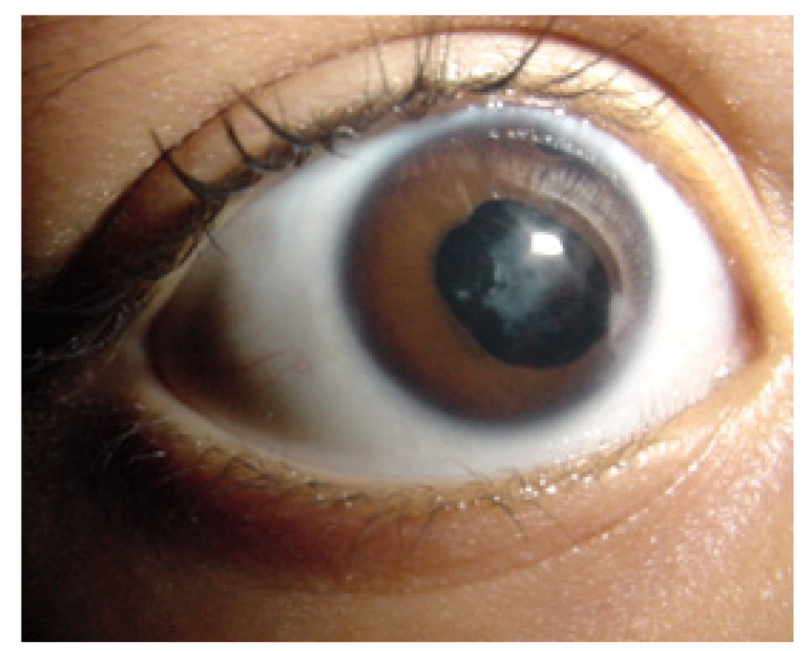

Figure I Case 3: unilateral leukocoria secondary to anterior chamber hyphema caused by juvenile xanthogranuloma. 
Visual acuity improved to 20/40 eight months after surgery. Clinical diagnosis was idiopathic prelenticular membrane formation.

\section{Case 6}

A 47-month-old girl presented with unilateral leukocoria in left eye. Visual acuity was LogMAR 0.60 (Snellen 20/80). Slit-lamp examination disclosed prelenticular membrane with partially affected visual axis. The lesion remained stable during 6 months of clinical observation. No inflammatory or uveitis signs were observed. No surgical treatment was performed in this patient. Indirect ophthalmoscopy and ultrasonography were both normal in the affected eye. Clinical diagnosis was unilateral leukocoria due to idiopathic prelenticular membrane formation.

\section{Case 7}

A 2-month-old girl presented with a facial hemangioma affecting the right upper lid region and unilateral leukocoria in right eye. Visual acuity was LogMAR 1.45 (Snellen 20/570). Slit-lamp examination showed multiple reddish nodular iris lesions compatible with iris hemangiomas. Prelenticular membrane formation partially affecting the visual axis was observed. Indirect ophthalmoscopy and ultrasound examinations were normal in the affected eye. Clinical diagnosis was unilateral leukocoria due to prelenticular membrane formation probably secondary to hemorrhages from the iris hemangioma lesions. The membrane formation could be related to repeated anterior chamber hyphema resolution.

\section{Case 8}

An 8-month-old boy presented with unilateral limbic dermoid associated with a partial visual axis opacification. He was referred to the clinic for cataract surgery. A congenital dense membrane formation located supra nasally at the pupillary area was noted anterior to the lens. Surgery was performed for membrane removal and the lens remained clear after the procedure. Clinical diagnosis was unilateral leukocoria due to idiopathic prelenticular membrane formation.

\section{Case 9}

A 2-month-old girl was referred to the clinic due to leukocoria in her left eye. A partial pupillary membrane anterior to the lens was present. The membrane presented dilated vessels and posterior synechiae. Clinical diagnosis of this pre-lenticular leukocoria condition was absence of involution of anterior segment persistent fetal vasculature (PFV).
Partial time occlusion therapy and use of topic mydriatic agent were indicated.

\section{Results}

This study describes nine patients that were formerly diagnosed as having leukocoria due to suspected cataracts.

All children were under 4 years old and presented with unilateral prelenticular leukocoria without lens opacification. All cases had normal ophthalmoscopy and normal posterior segment ultrasonography in the affected eye.

Among the patients, three had idiopathic prelenticular membrane, two presented with juvenile xanthogranuloma with secondary pupillary membrane, one had persistent fetal pupillary membrane, one had prelenticular membrane due to congenital toxoplasmosis, one presented with a pupillary membrane due to hyphema caused by iris hemangioma, and one had anterior segment persistent fetal vasculature. The main clinical diagnosis and ophthalmological findings in our group of patients are disclosed in Table 1.

\section{Discussion}

Leukocoria is another name for a white pupil, which is clinically determined by visual axis opacification at the pupillary area. Leukocoria, which is an important sign in several significant pediatric ocular conditions, is a dangerous condition demanding immediate attention because a number of affected children may have pathologies that are either lifethreatening (such as retinoblastomas) or cause permanent visual disabilities.

Table I Clinical diagnosis of prelenticular leukocoria and characteristics of the included patients

\begin{tabular}{|c|c|c|c|}
\hline Patients & $\begin{array}{l}\text { Age at } \\
\text { leukocoria } \\
\text { diagnosis } \\
\text { (months) }\end{array}$ & $\begin{array}{l}\text { Affected } \\
\text { eye }\end{array}$ & $\begin{array}{l}\text { Prelenticular leukocoria } \\
\text { clinical diagnosis }\end{array}$ \\
\hline I & 3 & RE & $\begin{array}{l}\text { Persistent fetal pupillary } \\
\text { membrane }\end{array}$ \\
\hline 2 & 3 & LE & Congenital toxoplasmosis \\
\hline 3 & 36 & LE & Juvenile xanthogranuloma \\
\hline 4 & 6 & LE & Juvenile xanthogranuloma \\
\hline 5 & 14 & LE & $\begin{array}{l}\text { Idiopathic prelenticular } \\
\text { membrane }\end{array}$ \\
\hline 6 & 47 & LE & $\begin{array}{l}\text { Idiopathic prelenticular } \\
\text { membrane }\end{array}$ \\
\hline 7 & 2 & RE & Iris hemangioma \\
\hline 8 & 8 & RE & $\begin{array}{l}\text { Idiopathic prelenticular } \\
\text { membrane }\end{array}$ \\
\hline 9 & 2 & LE & Anterior segment PFV \\
\hline
\end{tabular}

Abbreviations: RE, right eye; LE, left eye; PFV, persistent fetal vasculature. 
Leukocorias are related to congenital cataracts, retinoblastomas, ocular toxocariasis, ocular toxoplasmosis, retinopathy of prematurity, retinal hamartomas, PFV, Coats' disease, corneal scars (leucoma), retinal detachment, vitreous hemorrhage, retinochoroidal colobomata, familial exudative vitreoretinopathy, Norrie's disease, and other differential

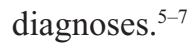

In our study, leukocoria was described as any ocular condition with visual axis opacification producing a white pupil and causing abnormal findings on a red reflex test (Brückner test). ${ }^{8-10}$

The study included nine patients, all children, with unilateral prelenticular leukocoria caused by different conditions without association with cataracts or retrolental abnormalities. None of these patients could be included in the current classification of leukocoria, which is identified as either lenticular or retrolenticular leukocoria.

The etiology of prelenticular leukocoria may be a challenge in some cases, as it can be the result of a pre-existent intraocular inflammatory disease. There are several causes related to prelenticular leukocoria, and these can include congenital persistent pupillary membrane or remnants of fetal pupillary membranes. Anterior segment PFV may also be considered when fibrovascular membranes are formed beneath the iris. ${ }^{11}$ Patients with juvenile xanthogranuloma and iris hemangioma presented with pupillary fibrin membranes possibly secondary to anterior chamber hyphema reabsorption.

Three of the patients described in the present study presented with idiopathic prelenticular membrane (cases 5 , 6,8 ); two patients presented with juvenile xanthogranuloma with secondary pupillary membrane (cases 3,4 ); one patient had a persistent fetal pupillary membrane (case 1); one patient had a prelenticular membrane due to congenital toxoplasmosis (case 2); one patient presented with a pupillary membrane due to hyphema caused by iris hemangioma (case 7); and one patient presented with anterior segment PFV (case 9).

There are some patients that presented with leukocoria with associated conditions such as prelenticular inflammatory pupil membrane combined with lens opacification. There are other cases with lenticular opacification (cataract formation) associated with different retrolenticular diseases. Retinoblastoma, PFV, and posterior uveitis can cause retrolenticular leukocoria, and may occur in combination with secondary cataract formation. When more than one clinical finding of leukocoria affects the same eye we can have combined or mixed presentation
Table 2 Proposal of a novel classification for leukocoria
I. Pre-lenticular leukocoria
2. Lenticular leukocoria
3. Retrolenticular leukocoria
4. Mixed presentation leukocoria

forms of leukocoria. Pseudophakic or aphakic eyes may also develop opacifications in the visual axis (posterior capsular opacification, intraocular lens opacification or fibrin membrane anterior to the intraocular lens) producing a white pupil. All of the patients described in the current study could not be included in the former classification of lenticular or retrolental leukocorias. It might be necessary to revisit the classification of leukocoria.

In this study, a new classification of leukocoria including prelenticular and mixed presentation leukocoria is proposed. This novel classification allows for an earlier correct diagnosis leading to the implementation of better surgical strategies to avoid unnecessary clear lens removal. The earlier achievement of a clear visual axis is of great importance for amblyopia treatment in children with prelenticular leukocoria. To anticipate surgical strategies, the ultrasound biomicroscopy examination can help in the diagnosis of prelenticular leukocoria cases. If there is any evidence of pupillary membrane, an ultrasound biomicroscopy examination should be mandatory in order to avoid clear lens extraction in children. The herein proposed novel classification of leukocorias is displayed in Table 2.

\section{Disclosure}

The authors declare no financial support or relationships that may pose a conflict of interest. Authors also certify that the protocol for the research project has been approved by a suitably constituted Ethics Committee of the institution within which the work was undertaken and that it conforms to the provisions of the Declaration of Helsinki in 1995 (as revised in Edinburgh 2000).

\section{References}

1. Balmer A, Munier F. Diagnosis and treatment of intraocular tumors in the child. Klin Monbl Augenheilkd. 2001;218(5):292-297.

2. Balmer A, Munier F. Leukokoria in a child: emergency and challenge. Klin Monbl Augenheilkd. 1999;214(5):332-335.

3. Shields JA, Parsons HM, Shields CL, Shah P. Lesions simulating retinoblastoma. J Pediatr Ophthalmol Strabismus. 1991;28(6):338-340.

4. Gao YJ, Qian J, Yue H, Yuan YF, Xue K, Yao YQ. Clinical characteristics and treatment outcome of children with intraocular retinoblastoma: a report from a Chinese cooperative group. Pediatr Blood Cancer. 2011; 57(7):1113-1116.

5. Servodidio CA, Abramson DH. Coats' disease. Insight. 1996;21(4): $112-113$. 
6. Abramson DH, Servodidio CA. Retinoblastoma in the first year of life. Ophthalmic Paediatr Genet. 1992;13(4):191-203.

7. Haider S, Qureshi W, Ali A. Leukocoria in children. J Pediatr Ophthalmol Strabismus. 2008;45(3):179-180.

8. Moshfeghi DM, Wilson MW, Haik BG, Hill DA, Rodriguez-Galindo C, Pratt CB. Retinoblastoma metastatic to the ovary in a patient with Waardenburg syndrome. Am J Ophthalmol. 2002;133(5):716-718.

9. Red reflex examination in infants. Section on Ophthalmology. American Academy of Pediatrics. Pediatrics. 2002;109(5):980-981.
10. American Academy of Pediatrics; Section on Ophthalmology; American Association for Pediatric Ophthalmology and Strabismus; American Academy of Ophthalmology; American Association of Certified Orthoptists. Red reflex examination in neonates, infants, and children. Pediatrics. 2008;122(6):1401-1404.

11. Kolin T, Murphee AL. Hyperplastic persistent pupillary membrane. Am J Ophthalmol. 1997;123(6):839-841.

\section{Publish your work in this journal}

Clinical Ophthalmology is an international, peer-reviewed journal covering all subspecialties within ophthalmology. Key topics include: Optometry; Visual science; Pharmacology and drug therapy in eye diseases; Basic Sciences; Primary and Secondary eye care; Patien Safety and Quality of Care Improvements. This journal is indexed on

Submit your manuscript here: http://www.dovepress.com/clinical-ophthalmology-journal

\section{Dovepress}

PubMed Central and CAS, and is the official journal of The Society of Clinical Ophthalmology (SCO). The manuscript management system is completely online and includes a very quick and fair peer-review system, which is all easy to use. Visit http://www.dovepress.com/ testimonials.php to read real quotes from published authors. 